\title{
Structural and vibrational properties of ettringite from classical atomistic simulations
}

\author{
EVGENY V. TARARUSHKIN ${ }^{1,2}$, DR. VASILY V. \\ PISAREV $^{1}$ AND ANDREY G. KALINICHEV ${ }^{1,3}$ \\ ${ }^{1}$ National Research University Higher School of Economics \\ ${ }^{2}$ HSE University \\ ${ }^{3}$ IMT Atlantique
}

Presenting Author: etararushkin@hse.ru

Ettringite is one of the common phases of cement and plays an important role in cement chemistry as the primary cause of sulfate corrosion in Portland cement. The formation of ettringite is accompanied by volume expansion and can lead to cracking and mechanical damage to concrete. Due to these important consequences of ettringite formation and evolution for the concrete durability, there is a need for a detailed understanding of these processes on the fundamental atomistic scale.

Ettringite, $\left(\mathrm{Ca}_{6}\left[\mathrm{Al}(\mathrm{OH})_{6}\right]_{2}\left[\mathrm{SO}_{4}\right]_{3} \cdot n \mathrm{H}_{2} \mathrm{O}, n=24-27\right)$, has a columnar crystal structure formed by stacked aluminum hydroxide and calcium hydroxide polyhedra. The hydroxide columns are held together by a network of hydrogen bonds formed by $\mathrm{H}_{2} \mathrm{O}$ molecules and sulphate ions that occupy the intercolumnar space of the crystal. The ClayFF force field [1] has been originally developed for atomistic computer simulations of clay and cement materials. Here we are using the new recent modification of this force field, ClayFF-MOH [2], which can now more accurately account for the bending of $\mathrm{Al}-\mathrm{O}-\mathrm{H}$ and $\mathrm{Ca}-\mathrm{O}-\mathrm{H}$ angles in the mineral structure.

The structural properties, the formation and breaking of hydrogen bonds and the vibrational spectra of ettringite are calculated by classical molecular dynamics simulations using this new ClayFF-MOH model and compared with a diverse set of available experimental data, including X-ray diffractometry, neutron scattering, IR and Raman spectroscopy, as well as earlier atomistic simulations [3-5].

The research was conducted within the framework of the HSE University Basic Research Program. The calculations were performed on the CHARISMa supercomputer of NRU HSE.

\section{References}

[1] Cygan R.T., Liang J.-J., Kalinichev A. G. (2004) J. Phys. Chem. B 108, 1255-1266.

[2] Pouvreau M., Greathouse J. A., Cygan R. T., Kalinichev A. G. (2017) J. Phys. Chem. C 121, 14757-14771.

[3] Kalinichev, A.G., and Kirkpatrick, R.J. (2002) Chemistry of Materials 14, 3539-3549.

[4] Mutisya, S.M., de Almeida, J.M., and Miranda, C.R. (2017) Computational Materials Science, 138, 392-402.

[5] Honorio, T., Guerra, P., and Bourdot, A. (2020) Cement and Concrete Research, 135, 106126. 